TO THE EDITOR, British Journal of Venereal Diseases

\section{Clostridium difficile in the genital tract}

Sir,

Recent studies of anaerobic bacteria in both the male and female genital tracts have included techniques for the isolation of Clostridium difficile. ${ }^{1-3} \mathrm{Hafiz}$ et al isolated $\mathrm{Cl}$ difficile from $71 \%$ of vaginal specimens from patients attending a sexually transmitted disease (STD) clinic and 18\% of women attending a family planning clinic, and from all of 42 men with non-specific urethritis (NSU). 4

The results of more recent studies have been contradictory. $\mathrm{Cl}$ difficile was isolated from only two out of 79 patients with balanoposthitis, and not at all from 24 men with NSU, 19 men with both NSU and balanoposthitis, or from 28 asymptomatic controls. ${ }^{2}$ Moreover, Moss failed to isolate $\mathrm{Cl}$ difficile from 20 men and 34 women attending an STD clinic. ${ }^{1}$ A vaginal carriage rate of $11 \%$ in consecutive female patients attending an STD clinic and $18 \%$ in pregnant women was reported by O'Farrell et al using a selective broth medium. ${ }^{3}$ In this laboratory 206 vaginal swabs from 187 women, and urethral swabs from 20 men attending a special clinic were examined for $\mathrm{Cl}$ difficile. Swabs were broken off into cooked meat broth and incubated at $37^{\circ} \mathrm{C}$ for five days before subculture on to modified CCFA medium, 56 but $\mathrm{Cl}$ difficile was not isolated from any specimen.

There exists an apparent dichotomy between the high carriage rates observed in both symptomatic and asymptomatic populations, 34 and the negligible isolation rates encountered in this and other laboratories. 12 This discrepancy might be explained by the use of isolation techniques of differing sensitivities, but the methods of Moss $^{1}$ and Masfari et $a l^{2}$ were essentially similar to those employed by Hafiz et al, 4 and all recent investigations including the present one used enrichment culture and a highly efficient selective medium. The existence of a geographical variation in urogenital carriage of $\mathrm{Cl}$ difficile remains a possibility and requires further study.

Yours faithfully,

$P$ N Levett

PHLS Anaerobe Reference Unit,

Public Health Laboratory,

Luton \& Dunstable Hospital, Lewsey Road,

Luton LU4 0DZ

\section{References}

1. Moss S. Isolation and identification of anaerobic organisms from the male and female urogenital tracts. Br J Vener Dis 1983;59: 182-5.

2. Masfari AN, Kinghorn GR, Duerden BI. Anaerobes in genitourinary infections in men. Br J Vener Dis 1983;59:255-9.

3. O'Farrell S, Wilks M, Nash JQ, Tabaqchali S. A selective enrichment broth for the isolation of Clostridium difficile. J Clin Pathol 1984; 37:98-9.

4. Hafiz S, McEntegart MG, Morton RS, Waitkins SA. Clostridium difficile in the urogenital tract of males and females. Lancet 1975; i: 420-1.

5. Phillips KD, Rogers PA. Rapid detection and presumptive identification of Clostridium difficile by $p$-cresol production on a selective medium. J Clin Pathol 1981;34: 642-4.

6. Levett PN. Use of enrichment cultures for the isolation of Clostridium difficile from stools. Microbios Letters 1984 (in press).

TO THE EDITOR, British Journal of Venereal Diseases

\section{Case reports of urethritis}

\section{Sir,}

We should like to comment on two articles in the February 1984 issue of the journal. We agree with Drs M N H Chowdhury and S S Pareek (pp 56-7) that recovery of group B streptococci from the patient with urethritis and from his wife, in the absence of other identifiable pathogenic microorganisms, together with the successful response to penicillin, suggest a causal relation. There are, however, several aspects which are not clear. The details of the history of urethritis are insufficient to know whether it was consistent or intermittent in severity. Is it not feasible that the response to treatment was more apparent than real and coincided with a natural remission? A longer follow up period would have been helpful in making this assessment. Both patients were free from symptoms after three weeks (of being seen initially?), but were they free from signs of disease and organisms too? We are not told. Furthermore, an important aspect is the sensitivity of procedures which rule out the possibility of other micro-organisms being implicated. To know that chlamydiae were being isolated in the laboratory from other patients with urethritis or cervicitis at rates consistent with those recorded by workers elsewhere would put the negative result in this case into perspective. In addition, to know that culturing for gonococci was negative would have been helpful, as would assessment of the anaerobic flora. We see nothing wrong in presenting a case report, but when the intention is to
British Journal of Venereal Diseases

persuade the reader about the aetiology of disease there is a greater onus to set out the data explicitly so that there is ant opportunity for making a balanced judget ment.

$\stackrel{\text { C) }}{+}$

The second article, by Drs D W Spelmaga and D Bradford (pp 58-9), on urethritis in patient with agammaglobulinaemia was particular interest to us because we havo previously described genitourinary disease including non-gonococcal urethritis, in patients with hypogammaglobulinaemia. 12 In the case described, it is difficult to resolve the question of whether the in provement in the patient's condition coul be attributed to intraurethral instillation of immunoglobulin. Irrigation with salinio might have afforded the same symptomatic improvement. Resolution of signs of disease based on quantitative analysis of leukocytes in discharge and urine samples would have been more convincing. Further more, it seems unlikely that immunoglobulin, which would remain only tran\& iently in the urethra because of urination could gain access to paraurethral gland and the prostate where putative pathogens are likely to shelter and then emerge. Tho administration of doxycycline together with intraurethral immunoglobulin aftep ureaplasmas were eventually foun eliminates any possibility of knowin whether the immunoglobulin was respon\$ ible for subsequent ureaplasma negatiof cultures, unless the ureaplasmas were resistant to tetracycline. It is unfortunate that much of the microbiological invest gation in this case came late so that it impossible to know what micro-organism(घ) might have been responsible for the start of disease or for its longevity. Our experience however, shows that ureaplasmas are ab $\bar{E}$ to multiply and attain large numbers $(\geqslant 10 \%$ in the urethra of hypogammaglobulinaeme patients, and to cause urethritis. It will be difficult to resolve the question of whethes local irrigation with pooled immunoglo bulin is effective in treating this conditio because this would entail withholding anti biotics from affected patients. We wouldg not recommend such a trial as ureaplasmas may travel to joints and cause septio arthritis. ${ }^{3}$ Some rational basis for local treatment, however, would be the showing that pooled immunoglobulin contains ants body to the strain of organism implicated: Yours faithfully

D Taylor-Robinsón $P M$ Fuff A D B Webstê

MRC Clinical Research Centre, Watford Road, Harrow, Middlesex HAl 3UJ 